\title{
New Growth Features of Poly(3-hydroxybutyrate-co-3-hydroxyhexanoate) Banded Spherulites
}

\author{
Jun Xu, Bao-Hua GuO, Guo-Qiang CHEN, ${ }^{*}$ and Zeng-Min ZHANG ${ }^{\dagger}$ \\ Institute of Polymer Science and Engineering, Department of Chemical Engineering, \\ School of Materials Science and Engineering, Tsinghua University, Beijing 100084, China \\ ${ }^{*}$ Department of Biological Sciences and Biotechnology, Tsinghua University, Beijing 100084,China
}

(Received January 14, 2003; Accepted March 10, 2003)

\begin{abstract}
KEY WORDS Polyhydroxyalkanoates / Banded Spherulites / Template / Crystallization / Phase Contrast Light Microscope /
\end{abstract}

Banded spherulites are commonly found in polymer systems, such as polyethylene, ${ }^{1}$ polypropylene, ${ }^{2}$ poly(ethylene oxide), ${ }^{3} \alpha$-type poly(vinylidene fluoride) ${ }^{4}$ optically pure poly(epichlorohydrin $)^{5}$ and miscible blends of poly( $\varepsilon$-caprolactone) and poly(styrene$c o$-acrylonitrile), ${ }^{6}$ etc. In microbial polyesters, such as poly(3-hydroxybutyrate) and poly(3-hydroxybutyrateco-3-hydroxyvalerate), ${ }^{7}$ banded spherulites are usually observed. The phenomena causing such banded spherulites were interpreted by the twisted crystal model. ${ }^{1,8-10}$ The ringed bands were attributed to the helicoidal twist of radial lamellar ribbons. According to Keith et al., ${ }^{11}$ twisted crystallization results from the stress building during crystallization, probably within disordered fold surfaces of polymer crystals. Though this model has been generally accepted, the mechanism of cooperative stacking of the twisted lamellae is still unclear.

To further investigate the mechanism of banding, real-time study of growth was conducted. Low growth rate of poly(3-hydroxybutyrate-co-3hydroxyhexanoate) (PHBHHx) banded spherulites allows a convenient real-time study. In this paper, new growth features of PHBHHx are reported for the first time.

\section{EXPERIMENTAL}

PHBHHx was supplied by Procter \& Gamble Co. The polymer was produced by Aeromonas hydrophila 4AK4, with $M_{\mathrm{n}}=316700$ and $M_{\mathrm{w}}=2083500$. The glass transition, melting temperature, and crystallinity was measured to be $-3.2^{\circ} \mathrm{C}, 115.3^{\circ} \mathrm{C}$, and $25 \%$, respectively.
The sample was melted between two glass slides at $220^{\circ} \mathrm{C}$ for $3 \mathrm{~min}$ (temperature was chosen to suppress melt viscosity for convenience of two-dimensional sample preparation) and then quickly transferred onto a hot stage preset at $90^{\circ} \mathrm{C}$. After crystallization at $90^{\circ} \mathrm{C}$ for $36 \mathrm{~h}$, the banded spherulites impinged on each other, and then the sample was quenched to room temperature and observed under the phase contrast light microscope (Olympus BH-2, Japan). New bands continued to grow on the spherulites at room temperature. The micrographs of the in situ growth of the new bands were obtained via a charge coupled detector (CCD) camera (Sanyo, Japan) connected to a computer.

Atomic force microscopy (AFM) was applied to obtain details about the surface. The sample was dipped in ice water for $10 \mathrm{~min}$, and upper slide was gently removed. Topography was done directly under tappingmode AFM using a Nanoscope III MultiMode AFM (Digital Instruments). Height images were recorded with retrace signals. A tapping-mode etched silicon (TESP) tip with resonance frequency of approximately $300 \mathrm{KHz}$ and spring constant of about $30 \mathrm{~N} \mathrm{~m}^{-1}$ was used.

\section{RESULTS AND DISCUSSION}

After the PHBHHx was melt crystallized at $90^{\circ} \mathrm{C}$ for $36 \mathrm{~h}$, all spherulites were observed to impinge on the neighboring spherulites. Since we did not have a phase contrast light microscope with hot stage, the sample was quenched and observed under a phase contrast light microscope at room temperature. Still some amorphous melt remained after the first crystallization at $90^{\circ} \mathrm{C}$ and it continued to crystallize to form new bands

${ }^{\dagger}$ To whom correspondence should be addressed(E-mail: zhangzm@mail.tsinghua.edu.cn). 


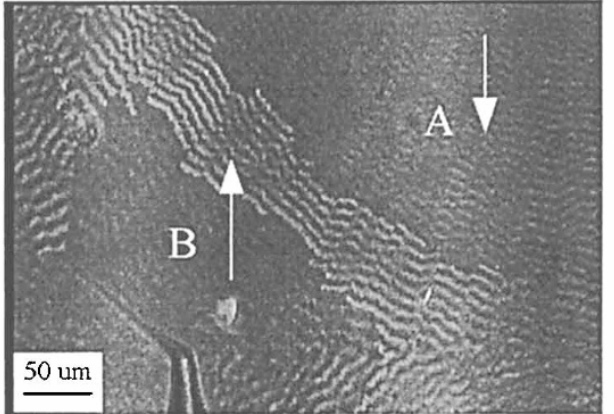

$t=0 \mathrm{~min}$

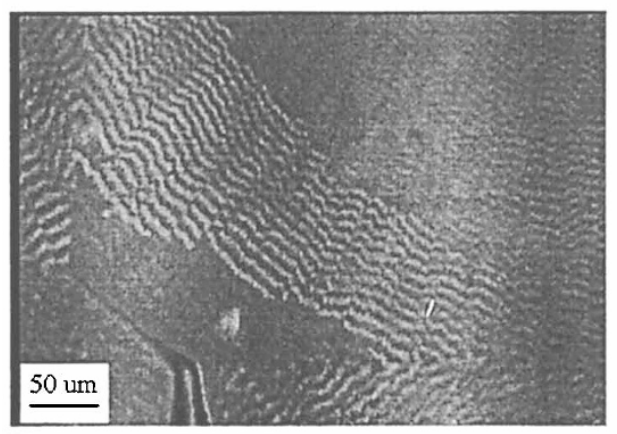

$t=86 \min$

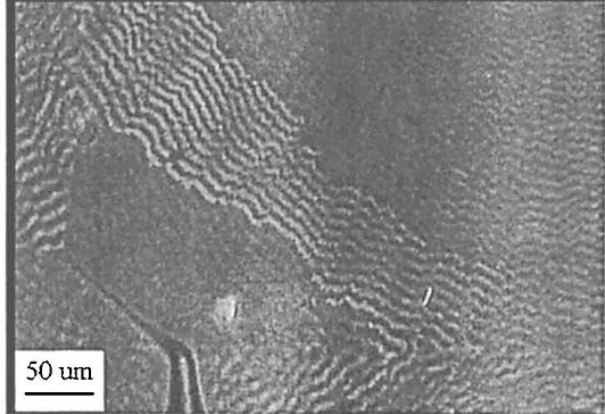

$t=32 \mathrm{~min}$

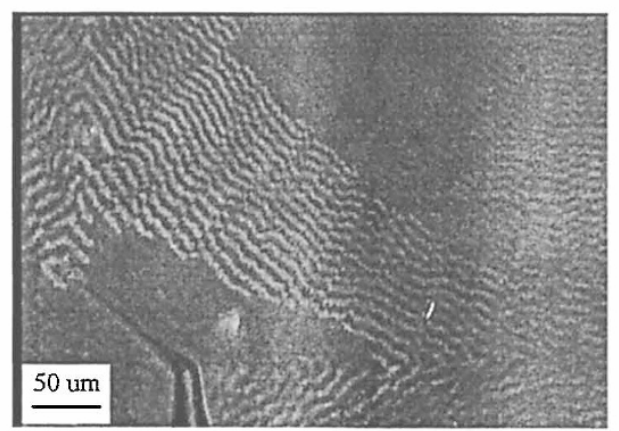

$t=140 \mathrm{~min}$

Figure 1. In situ observation on growth of bands at room temperature after spherulites were crystallized at $90^{\circ} \mathrm{C}$ for $36 \mathrm{~h}$ and observed to impinge on each other. Arrow A indicates bands formed at $90^{\circ} \mathrm{C}$ and arrow B indicates bands growing at room temperature. The same region was photographed at different time, as below for each image.

between the crystallized layer and upper glass slide at room temperature. The phase contrast light microscope showed two layers on a PHBHHx banded spherulite, namely, the dark layer crystallized at $90^{\circ} \mathrm{C}$ (arrow A in Figure 1) and the bright layer growing at room temperature (arrow B in Figure 1). Why the spherulite grew two-dimensionally to form layers is still unclear. The height of the new layer was determined as around $110 \mathrm{~nm}$ (Figure 2), which is small compared to the total sample thickness of $10 \mu \mathrm{m}$. Thus, after the first crystallization at $90^{\circ} \mathrm{C}, 99 \%$ of the sample was crystallized and only $1 \%$ left amorphous between the first layer and the upper glass slide. When quenched to room temperature, the amorphous part continued to crystallize to form bands.

In Figure 1, the new layer has started growth from the edge region rather than from the center of the banded spherulite, growing forward, and backward. The orientation of the bands in the newly formed layer was closely related to the existing bands. In other words, the existing bands acted as templates for the growth of the new bands. Since the thickness of a single lamella of PHBHHx was less than $10 \mathrm{~nm}$, the banded spherulites in the sample with thickness of several microns would consist of many layers of lamellae. If the layers are randomly deposited in depth, for example, if edge-on lamellae formed on flat-on lamellae, the dis-

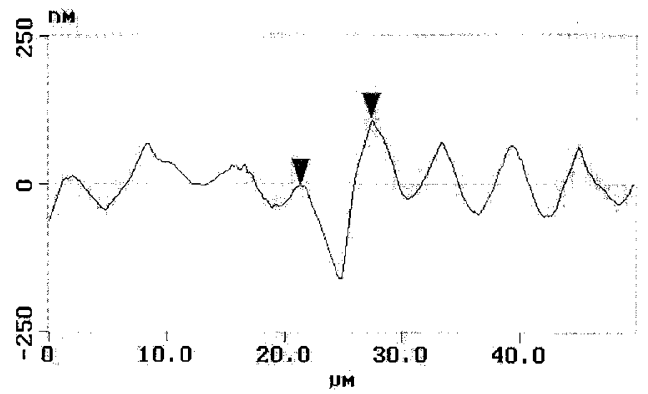

(a)

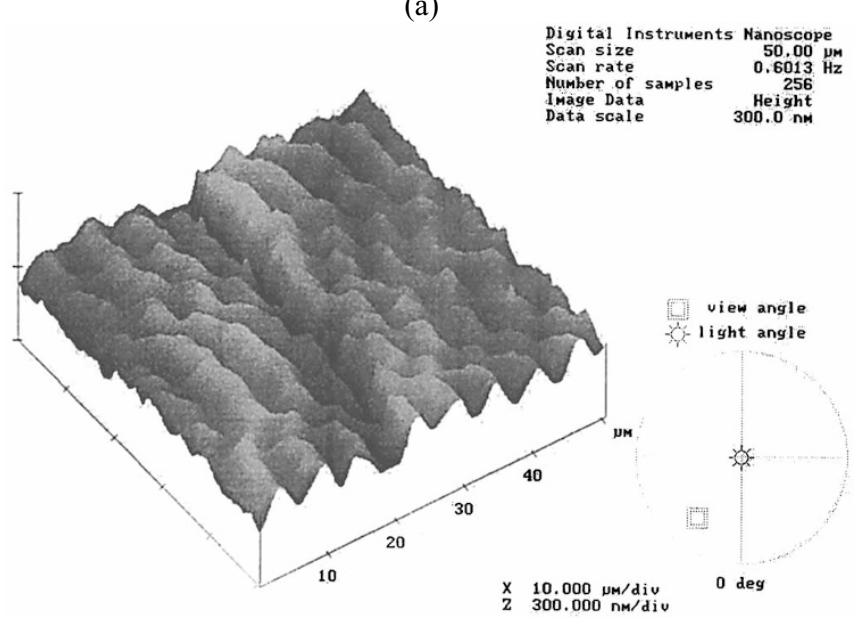

(b)

Figure 2. AFM height images of a banded spherulite consisted of two layers. (a) Cross section showing height profile; (b) Threedimensional image. 


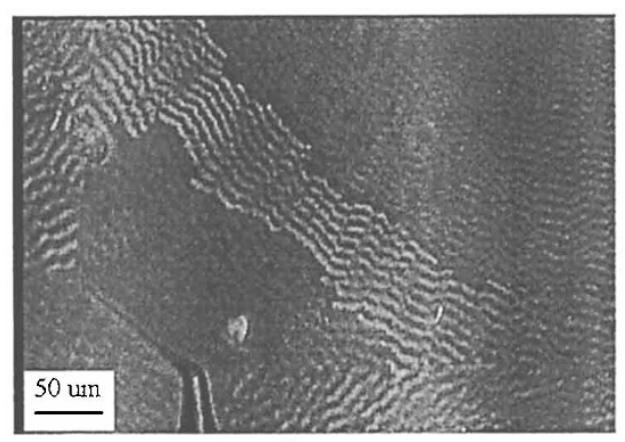

$t=8 \min$

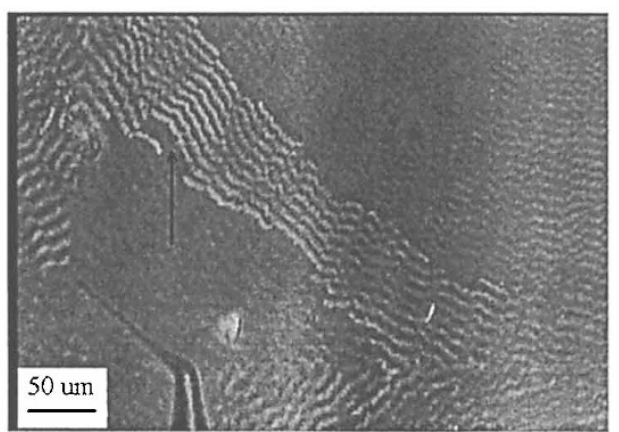

$t=10 \mathrm{~min}$

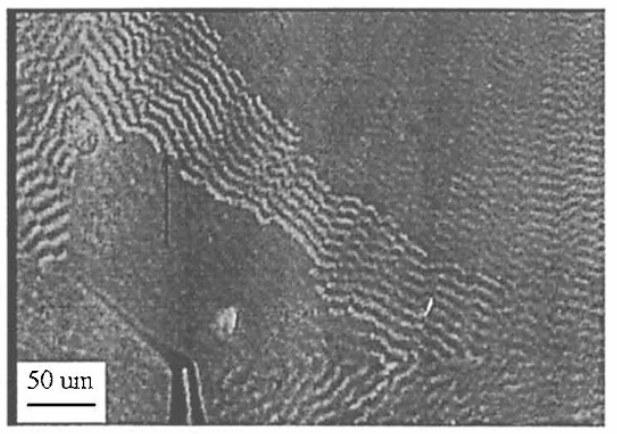

$t=18 \mathrm{~min}$

Figure 3. A series of micrographs showing filling of a band. The arrow indicates filling site. The three micrographs are in the same run as those in Figure 1 and were obtained between $t=0 \mathrm{~min}$ and $t=32 \mathrm{~min}$.

order packing should lead to common spherulitic morphology without extinction rings. Twisting would not lead to in-phase stacking, and thus the template effect may lead to in-phase stacking of the twisted lamellae in banded spherulites.

The new bands formed at room temperature had the same band spacing of about $10 \mu \mathrm{m}$ compared to existing bands formed at $90^{\circ} \mathrm{C}$. When PHBHHx was isothermally crystallized at room temperature, the band spacing was only $0.6 \mu \mathrm{m}$ based on static light scattering. The light scattering maxim appeared at $63.7^{\circ}$ and the band spacing was calculated as:

$$
P=\lambda /(2 \sin (\theta / 2))
$$

where $P$ is band spacing, $\lambda$ wavelength of the laser, $0.633 \mu \mathrm{m}$ and $\theta$ azimuthal angle of the scattering maxim. The small band spacing of $0.6 \mu \mathrm{m}$ could not be distinguished under the light microscope. Pre-existing bands thus determine not only orientation but also spacing of newly formed bands.

The formation of new bands was investigated in situ via the video camera. Figure 3 shows that the new band preferably formed next to an existing band or at one end of the old band. The three micrographs in Figure 3 are in the same run as those in Figure 1 and obtained between $t=0 \mathrm{~min}$ and $t=32 \mathrm{~min}$. The bands usually appeared one by one in the radial direction; however, sometimes a band was missing, but turned up again later, as shown by the arrow in Figure 3.

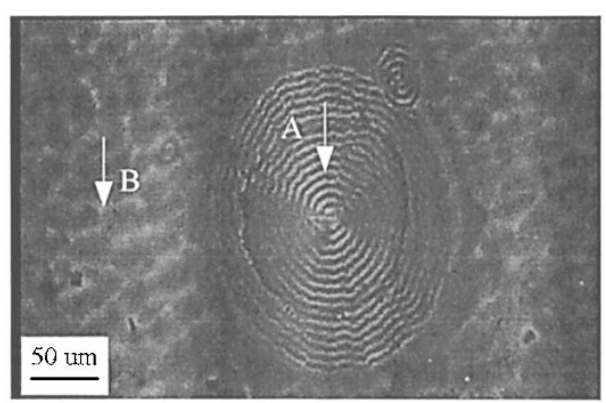

(a)

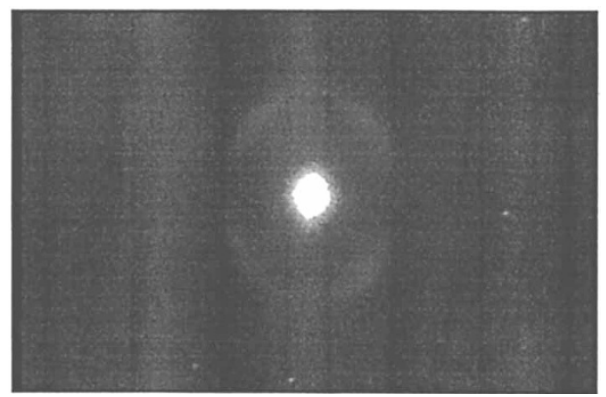

(b)

Figure 4. Optical micrograph (a) and Hv light scattering pattern (b) of the spherulites formed at room temperature after semicrystallized at $90^{\circ} \mathrm{C}$ for $8 \mathrm{~h}$. Arrow A indicates a spherulite crystallized at $90^{\circ} \mathrm{C}$, and arrow B indicates spherulites crystallized at room temperature. Image (b) is a region-selective Hv light scattering pattern of the spherulites crystallized at room temperature.

The formation of new bands was closely correlated to existing bands, this being the template effect described above. To further examine the mechanism, a sample 


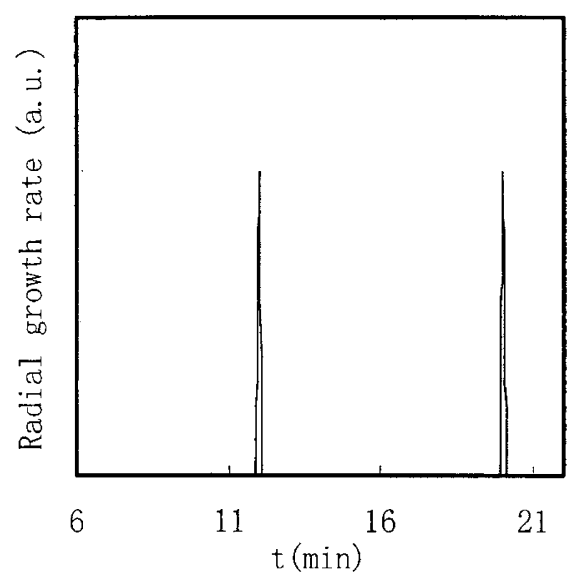

Figure 5. Pulsate growth rate of the new layer (arrow B in Figure 1) in the radial direction.

crystallized at $90^{\circ} \mathrm{C}$ for $8 \mathrm{~h}$ was quenched to room temperature before impingement of spherulites (arrow A in Figure 4a). The sample continued to crystallize at room temperature to form spherulites with band spacing considerably decreased (arrow B in Figure 4a), to be $0.6 \mu \mathrm{m}$ from light scattering (Figure $4 \mathrm{~b}$ ). This small band spacing is the same as that in the sample kept crystallization wholly at room temperature. Since there exists only an interface and no constraint on the amorphous part, the template effect was absent. Another sample sandwiched between two glass slides was completely crystallized at $90^{\circ} \mathrm{C}$, and then a glass slide was gently detached. The slide with the crystallized film on it was pressed onto a melted film, and the sample was then crystallized at $90^{\circ} \mathrm{C}$. The new layer had no observable correlation to the old layer. The template effect thus comes about during crystallization at $90^{\circ} \mathrm{C}$. Due to the spatial constraint and intermolecular entanglements, the amorphous part near the crystalline layer formed an intermediate state, in which the chain stems had the same orientation profile as those in the crystalline layer. Thus, when the intermediate state crystallized at room temperature, it had the same spacing as pre-existing bands formed at $90^{\circ} \mathrm{C}$.

The new layer consisting of many bands grew at a pulsate rate rather than at a constant rate (Figure 5). A part of a band formed quickly within 1 to $2 \mathrm{~s}$. Once the band appeared, no widening could be observed. It means that the band with a width of $10 \mu \mathrm{m}$ formed almost simultaneously. Due to the short time interval, the growth rate was hard to be determined, and thus the vertical coordinate in Figure 5 was scaled with an arbitrary unit. Band growth usually stopped for 4-6 min and then started again.

Hobbs et al. reported that the single lamellae of poly(hydroxybutyrate-co-hydroxyvalerate) showed non-continuous growth when crystallization of the sample was observed under an atomic force microscope. ${ }^{12}$ The leading lamellae initially spurted forward at a substantially greater rate than the macroscopic growth rate, and then slowed down or even stopped. But here, non-continuous growth was observed at the dimension up to $10 \mu \mathrm{m}$. The band observed under phase contrast light microscope consisted of edge-on lamellae and the region between two neighboring bands consisted of flat-on lamellae, as determined by atomic force microscopy. Non-continuous growth would thus appear due to variation of lamellar orientation. It was most likely that in the direction perpendicular to glass slide, the edge-on lamellae grew faster than the flat-on lamellae, leading to pulsate growth of bands.

\section{CONCLUSIONS}

New growth features of PHBHHx banded spherulites were observed during two-stage crystallization. The spherulites consisted of two layers, with new layer sometimes originating from the edge region and growing forward and backward. Though the new layer crystallized at room temperature, it still showed the same band spacing as that crystallized at $90^{\circ} \mathrm{C}$ due to the template effect of the old layer. A new band formed preferably next to an existing band or at one end of the old band. The template effect led to in-phase stacking of the radial twisting lamellae, bringing about regular bands observed under polarized light microscope.

The new layer grew at a pulsate rate. It spurted out at a greater rate for 1-2 s, and ceased for several min. The non-continuous growth may result from variation of lamellar orientation in the radial direction of the banded spherulites.

Acknowledgment. The authors are grateful to the anonymous reviewers for their suggestive comments. This work was partially supported by the Funds of Tsinghua University for Fundamental Scientific Research.

\section{REFERENCES}

1. H. D. Keith and F. J. Padden, J. Polym. Sci., 39, 101 (1959).

2. H. D. Keith and F. J. Padden, Polymer, 25, 28 (1984).

3. J. D. Ding, J. X. Zhu, and Y. L. Yang, Chem. J. Chin. Univ., 17, 498 (1996).

4. H. D. Keith, Macromolecules, 12, 919 (1979).

5. K. L. Singfield, J. M. Klass, and G. R. Brown, Macromolecules, 28, 8006 (1995).

6. Z. G. Wang, X. H. Wang, D. H. Yu, and B. Z. Jiang, Polymer, 38, 5897 (1997).

7. H. Bauer and A. J. Owen, Colloid. Polym. Sci., 266, 241 (1988).

8. A. Keller, J. Polym. Sci., 39, 151 (1959). 
9. H. D. Keith and F. J. Padden, Macromolecules, 29, 7776 (1996).

10. A. J. Owen, Polymer, 38, 3705 (1997).

11. H. D. Keith, F. J. Padden, and T. P. Russell, Macromolecules,
22, 666 (1989).

12. J. K. Hobbs, T. J. Mcmaster, M. J. Miles, and P. J. Barham, Polymer, 39, 2437 (1998). 